\title{
Cardiac Involvement in Progressive Muscular Dystrophy of the Duchenne Type
}

\author{
Kyozo Ishikawa, MD, FACG
}

\begin{abstract}
SUMMARY
Duchenne's progressive muscular dystrophy (DMD) is a genetic muscle disorder that causes degeneration and atrophy of the systemic and cardiac muscle. The disease is manifested early in childhood, and most of patients die by age 20 years of respiratory failure or heart failure. The cardiac involvement in DMD is characterized pathologically by degeneration and fibrosis of the myocardium, centering around the posterolateral wall of the left ventricle. Functionally, an abnormal electrocardiogram, valve motion, wall thickness, and wall motion are observed. Furthermore, abnormalities in plasma levels of atrial natriuretic peptide and autonomic function are also demonstrated.

In this review, the cardiac involvements in DMD in the following aspects are described: 1) Electrocardiogram; a) high-frequency notches on the QRS complexes, b) amplitude of QRS complexes, c) late potential, d) arrhythmias, e) heart rate variability, f) a 10-year follow-up study, 2) Echocardiographic findings, 3) Hemodynamic findings, 4) Atrial natriuretic peptide. (Jpn Heart J 1997; 38: 163-180)
\end{abstract}

Key words: Progressive muscular dystrophy, Cardiac involvement, Duchenne type

$\mathrm{P}$ ROGRESSIVE muscular dystrophy of the Duchenne type (DMD) is a recessive sex-linked familiar disorder that is characterized pathologically by skeletal and cardiac muscle degencration with fibrous tissue replacement and fatty infiltration. The onset of the disease occurs in early childhood, and most patients die at about 20 years of age. About $90 \%$ of the patients die of respiratory failure and the rest die of heart failure. ${ }^{1,2)}$

Cardiac involvement in DMD patients is a common finding. It is clinically important to clarify how myocardial degeneration affects cardiac function and prognosis.

In this communication, I will describe clinical observations of cardiac involvement in DMD.

From the Second Department of Internal Medicine, Kyorin University School of Medicine, Tokyo, Japan. Address for correspondence: Kyozo Ishikawa, MD, Second Department of Internal Medicine, Kyorin University School of Medicine, 6-20-2, Shinkawa, Mitaka-City, Tokyo 181, Japan.

Received for publication January 23, 1996.

Accepted January 30, 1996. 


\section{INVESTIGATIONS BY ElECTROCARDIOGRAPHY AND VECTORCARDIOGRAPHY}

High-frequency notches on the QRS complexes: As a result of the pioneering studies of Langner, ${ }^{3,4}$ Flowers, ${ }^{5,6)}$ Reynolds, ${ }^{7}$ Pipberber, ${ }^{87}$ Boyle, ${ }^{97}$ and others, high frequency notches (HFN) on QRS waves have gained wide interest. Abundant HFN are commonly associated with a variety of clinical situations such as cardiomyopathy, intraventricular conduction disturbance, myocardial ischemia and ventricular hypertrophy. It appears, therefore, that the notching is not caused by the presence of discrete lesions.

DMD patients are usually classified into eight stages from the mildest, $S(1)$, to the severest, $\mathrm{S}(8)$, according to Swinyard-Deaver's criteria. ${ }^{10 !}$ This classification is based on the pattern, ability and method of ambulation, and on activities of daily living.

We found the number of HFN on the QRS complexes increased with advancing severity of disease, until the pre-terminal stage. ${ }^{11)}$ In the terminal stage, $\mathbf{S}(8)$, however, we noted that the number of HFN tended to decrease. This led us to develop the hypothesis that during the usual clinical course of this disorder, the patient might tend to have a small number of HFN at the early stage, and then, with increasing severity of the disease, he might develop a larger number. In the terminal stage he might again exhibit relatively few notches. In the three-year follow-up study, ${ }^{12)}$ the general validity of our hypothesis has clearly been confirmed. It should be stressed, therefore, that careful evaluations of sequential changes in the count of HFN on the QRS complexes can be of prime importance in assessing the extent of cardiac involvement.

The precise mechanism by which the notching is produced remains unknown. However, several important investigations ${ }^{13-15)}$ have discussed the genesis of HFN on QRS complexes. Oppenheimer and Rothchild ${ }^{13\rangle}$ proposed the Purkinje block to explain interruption of the smooth progress of the wave of activation. Casella and Taccardi ${ }^{14)}$ showed that notching was observed only occasionally when the direction of the wave front was oriented parallel to the fibers and propagation was across the fibers. VanderArk and Reynolds ${ }^{15)}$ demonstrated experimentally that notching was produced by activation across, rather than along, myocardial fibers.

It is conceivable that progressive derangement of the myocardium by the disease process may provide more chances for cross-fiber activation resulting in a progressive increase in HFN. In the terminal stage, however, the severely deteriorated myocardium may no longer be adequate for cross-fiber activation, giving rise to a reduction in HFN.

The amplitude of QRS complexes: One of the most prominent sequential ECG changes in DMD is a progressive reduction in the magnitude of the left- 
ward QRS force, which is reflected by a decrease in the magnitudes of the $\mathrm{R}$ wave in lead X $(\mathrm{Rx})$, of the leftward force in the horizontal plane, and of the maximal QRS vector in the frontal plane. ${ }^{16)}$ It appeared reasonable to speculate that chest deformities, which are observed in almost all cases in the moderate and advanced stages, might shift the heart to the right side with a possible resultant decrease in the leftward force. Indeed, the chest transverse diameter (TD) and TD/SD (chest sagittal diameter) ratio tended to increasc with advancing clinical severity. However, it was shown in a previous study ${ }^{17}$ that an increase in TD led to an increase in the $\mathrm{Rx}$ amplitude, not a decrease in $\mathrm{Rx}$, and that the TD/SD ratio did not influence the $\mathrm{Rx}$ amplitude. Furthermore, close inspection of each subject indicated that there may be no direct correlation between the reduction of the Rx amplitude and the degree of chest deformity. Heymsfield and colleagues ${ }^{(8)}$ were unable to ascribe ECG changes in DMD to pectus excavatum, which is frequently associated with this disorder. Thus, it would appear that the chest deformities may not be the main determinant of the reduction of the leftward QRS force, although they might be partially involved. Sanyal and associates ${ }^{19)}$ revealed that progression of the disease would tend to be associated with myofibrillar loss of the left ventricular wall, which could account for a significant reduction in the leftward QRS force. Frankel and Rosser ${ }^{20)}$ demonstrated that in patients with this disorder, histologic evidence of degenerative changes appeared initially in the posterobasal segment of the left ventricle, subsequently spread to involve the outer third of the left ventricular free wall, and finally manifested itself as diffuse transmural fibrosis. Their observations may substantiate our findings that an anterior shift of the QRS forces appeared in the early stages and subsequently the leftward QRS force decreased with progression of the disorder. It seems justified to infer from these results that the decrease in the leftward QRS force might result mainly from myofibrillar loss of the left ventricular free wall, and that a progressive reduction of the $\mathrm{Rx}$ amplitude should be of predictive value in the assessment of the extent of cardiac involvement.

A distinctive ECG pattern consisting of tall $R$ waves in Leads $V_{1}, a V_{L}, V_{5}$, and $V_{6}$ has consistently been reported in 80 to 90 per cent of patients with

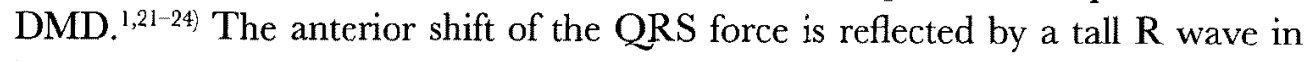
Lead $V_{1}$ of the standard 12-lead system and by a deep $Q$ wave in Lead $Z$ of the Frank lead system. In our previous study, ${ }^{16)}$ the frequency of observation of abnormal $Q$ waves in any one of the three leads (leads $X, Y$, and $Z$ ) was 93 per cent in the 70 cases. This finding is consistent with previous reports. ${ }^{1,21-24)}$ The pathogenesis of the abnormal $Q$ wave remains undetermined, although at present it seems most likely that replacement of normal cardiac tissue by fibrosis, with lateral extension of scarring, may explain the presence of $Q$ waves. ${ }^{23)}$ It should be pointed out that the occurrence of deep $Q$ waves was found to be quite high even 
in the early stages of DMD, and that it did not bear a direct relation to the sequential cvolution of the disorder. Thus, although the presence of a large $Q$ wave in the early stages represents a useful ECG sign for the early detection of DMD, it has only limited value in assessing the extent of cardiac involvement. Heymsfield and colleagues ${ }^{18)}$ made an extensive study of the scquence of cardiac changes in DMD. They pointed out that a tall $R$ wave in Lead $V_{1}$, and a deep $Q$ wave in Leads I, II, or $V_{5}$ are frequently observed both in patients with "early DMD" and those with "late DMD". Their observations are thus in agreement with our findings. ${ }^{16)}$

Late potential: Signal averaging, bandpass filtering, and high-gain electrocardiography have allowed the detection of high-frequency and low-amplitude signals in the terminal portion of the signal-averaged QRS complex. These are commonly termed late potentials (LPs). There is a large body of evidence to suggest that LPs recorded on the body surface represent areas of slow conduction in the myocardium, which are considered to represent the anatomic substrate for the reentry of ventricular tachycardia (VT). Much investigative attention has thus been focused on the association of LPs with VT. ${ }^{25-37)}$

We demonstrated that Holter monitoring revealed nonsustained VT at all stages of DMD, although ventricular premature contractions (VPCs) were strongly prevalent among DMD patients at advanced stages. ${ }^{38)}$ Although the details remain to be fully clarified, it seems likely that the increasing incidence of VPGs as the disease becomes more severe might simply indicate progressive derangement of the myocardium in DMD. The results of several studies ${ }^{39-42)}$ have demonstrated a correlation between the presence of LPs and ventricular dysfunction.

Breithardt et al. ${ }^{39)}$ reported LPs in $34 \%$ of 146 patients without $\mathrm{VT}$, of whom $22 \%$ had hypokinesis, $42 \%$ dyskinesis, and $4 \%$ akinesis. Zimmerman et al. ${ }^{40)}$ and Abboud et al. ${ }^{41)}$ also observed a higher prevalence of LPs in patients with LV aneurysms in the absence of VT. Our findings ${ }^{38)}$ are in agreement with these studies, in that the LPs in the DMD patients were closely associated with LV wall motion abnormalities as estimated from the total wall motion index (TWMI) obtained by two-dimensional echocardiography. The incidence of LPs was clearly greater in patients with dilated cardiomyopathy (DCM) than in the normal type. The TWMI was significantly higher in patients of the DCM type than in those of the normal and hypertrophic cardiomyopathy types, also indicating that the LPs were closely associated with LV dysfunction. In contrast, a lack of association between LPs and ventricular dysfunction has been reported by several investigators. ${ }^{32,35)}$

Histologic examinations of the myocardium exhibiting delayed, fragmented activation have revealed sparsely distributed but viable myofibrils encased in 
connective tissue, with a paucity of intercellular connections. ${ }^{43)}$ The cardiac lesions in DMD involve fatty and fibrous replacement of the myocardium, with selective scarring of the posterobasal portion of the LV and posteromedial papillary muscles, with or without lateral or inferior wall extension. ${ }^{1,20)}$

There are areas of compensatory myofiber hypertrophy, but most myocardial cells are atrophic, with loss of striation, vacuolation, fragmentation and nuclear degeneration. ${ }^{44}$ ) Thus, we considered that the source of the LPs in DMD patients was probably related to the amount of viable myocardium diffusely interspersed with fibrotic tissue. A correlation between VT and LPs could not be clarified from our study. ${ }^{38 ;}$

Arrhythmia: We reported that various types of cardiac arrhythmias can occur in patients with DMD and that severity of the arrhythmias increased with the progression of this disease. ${ }^{45}$ There have only been a few previous reports on the relationship of DMD to cardiac arrhythmias, and these were mainly of arrhythmias that were accidentally detected during 12-lead ECG recordings. ${ }^{1,21,46)}$ The first analysis of arrhythmias by 24-hour ambulatory electrocardiographic (AECG) monitoring was performed in 20 patients with DMD by Perloff. ${ }^{47} \mathrm{Al}-$ though his obscrvations agree with our findings in many respects, the relationship between the various arrhythmias and the severity or prognosis of DMD was not considered in Perloff's study.

Persistent sinus tachycardia, which is one of the rhythm disturbances that are commonly seen in $\mathrm{DMD}^{1,24,48,49)}$ was also observed in our investigation. ${ }^{45)}$ In patients with DMD persistent sinus tachycardia occurs, although patients are largely immobile because of skeletal muscle impairment, and their exercise tolerance is extremely reduced. The pathogenesis of this persistent tachycardia is unknown, but it may involve abnormalities of autonomic regulation. An alternative hypothesis, which has been proposed by Perloff, ${ }^{47}$ is that "dystrophic" sinoatrial node fibrosis and/or fatty infiltration causes not only abnormal sinus node automaticity but also sinus node reentry and labile sinus tachycardia.

The overall occurrence of atrial premature beats in the patients with DMD was not higher than that in normal young subjects, ${ }^{50,51)}$ but the percentage of patients with DMD with frequent atrial premature beats ( $>100$ beats in 24 hours) was higher at $18.8 \%$ than the $0 \%$ to $2 \%$ that is seen in normal subjects. ${ }^{50,51)} \mathrm{We}$ also demonstrated that the incidence increased as the severity of DMD progressed and that it increased from $38.3 \%$ to $74.5 \%$ during the 5 -year follow-up period. ${ }^{45)}$ In addition, ectopic atrial tachycardia and atrial fibrillation were both observed in patients with DMD, and these are arrhythmias that are very unusual in normal subjects. ${ }^{457}$ This finding has also been pointed out by other investigators, ${ }^{1,44,47)}$ and atrial arrhythmias are considered to be a characteristic of DMD. The pathogenesis of atrial arrhythmias in DMD seems to involve changes in 
small coronary blood vessels, which lead to lesions in the atrial conduction system, together with the increase in atrial pressure that is caused by respiratory or cardiac failure. ${ }^{44,52-54)}$

Transient first-and second-degree (type 1) atrio-ventricular (AV) block are arrhythmias that are often observed in normal subjects, ${ }^{50,51,55)}$ but the occurrence of these arrhythmias in patients with DMD is low and is not associated with highdegree AV block. ${ }^{45)}$ Furthermore, none of the 5-year survivors had AV block in our study. ${ }^{45)}$ Although cases of second-degree AV block (type 1) have previously been reported in patients with DMD, its occurrence is also low. ${ }^{47}$ As for highdegree AV block, only one report has described it in a patient with DMD who also had Wolf-Parkinson-White syndrome. ${ }^{56)}$ Our previous study suggests that DMD does not seriously interfere with the AV conduction system. ${ }^{45)}$ In fact, a short PR interval (less than $120 \mathrm{msec}$ ) has been reported as a characteristic of DMD. ${ }^{47-49)}$ We found that a short PR interval was observed in $40 \%$ of the subjects. ${ }^{45}$ Results of intracardiac electrophysiologic studies were not available for our patients, but the short PR interval may have been due to the presence of atriofascicular bypass tracts or accelerated conduction in the AV node. ${ }^{47,49)}$

The overall occurrence of ventricular arrhythmias in our patients with $\mathrm{DMD}^{44)}$ was not different from that reported in normal young subjects ${ }^{55}$ but the severity of the arrhythmias was higher in the patients with DMD. In particular, ventricular arrhythmias of grade $\mathrm{IVa}, \mathrm{IVb}$ and $\mathrm{V}$ showed a high rate of occurrence $(21.4 \%)$ in the terminal stage, $\mathrm{S}(8)$.

When the 5-year survivors were examined, the occurrence of malignant ventricular arrhythmias (i.e., grades IVa, $\mathrm{IVb}$ and V) was surprisingly found to have increased six-fold. ${ }^{45)}$ There have been few reports on malignant ventricular arrhythmias in patients with DMD, ${ }^{47)}$ but the onset of these in patients with advanced DMD was characteristic in our patients. ${ }^{45)}$ Myocardial degeneration, changes in the cardiac conduction system, increased irritability of the myocardium associated with noninflammatory vascular changes, mitral valve prolapse ${ }^{57}$. or hypoxia and increased ventricular loading as a result of respiratory or cardiac failure may all be possible mechanisms whereby ventricular arrhythmias develop in patients with DMD.

The sudden death syndrome was a significant cause of death in our series of patients with DMD. ${ }^{45}$ We often encounter sudden death in patients with DMD, but its relationship to arrhythmias remains unknown. It has conventionally been believed that one of the causes of sudden death in patients with cardiomyopathy and coronary artery disease is the occurrence of fatal ventricular arrhythmias such as ventricular tachycardia and ventricular fibrillation. ${ }^{58,59)}$ These fatal arrhythmias are triggered by malignant ventricular premature beats of grade IV or higher. ${ }^{58)}$ In three of the four patients with DMD who died suddenly during 
the 5-year follow-up period, malignant ventricular premature beats of grade IV or higher were observed during monitoring and the $\mathrm{R}$-on- $\mathrm{T}$ phenomenon was recorded in two of these three patients. No EGG data were recorded immediately before death in our cases, but it is possible that the cause of sudden death was fatal ventricular arrhythmias that were triggered by malignant ventricular premature beats or severe bradycardia.

Heart rate variability: Symptoms such as persistent or labile sinus tachycardia, sweating, and chilblains occur early in the course of DMD ${ }^{60}$ Although they suggest the presence of autonomic dysfunction, their precise etiology is not known. Important information on sympathovagal balance has been obtained in patients with diabetes mellitus ${ }^{61,62)}$ and ischemic heart disease ${ }^{63-65)}$ from an analysis of heart rate variability in the time and frequency domain.

The standard deviation (SD) of all normal RR intervals in the entire 24hour clectrocardiographic recording is influenced by short- and long-term trends in heart rate that is variously affected by respiration, vagal tone, diurnal influences, and other factors. Time domain measurements such as pNN50 (the proportion of adjacent cycles that are $>50 \mathrm{msec}$ apart, measured in percent) analyze the difference in successive $\mathrm{RR}$ intervals and are good indicators of parasympathetic tone. Among frequency domain measurements, the high frequency (HF) component is mediated by the parasympathetic system; the low frequency (LF) component is mediated by the sympathetic, parasympathetic and renin-angiotensin control systems. The $\mathrm{LF} / \mathrm{HF}$ ratio represents the sympathetic tone.

Circadian rhythm of time domain measurements: Time domain analysis revealed that the mean values for $R R$, the $S D$ of all normal $R R$ intervals in the entire 24-hour electrocardiographic recording, and pNN50 were lower at each stage of DMD compared with control values, indicating a decrease in parasympathetic tone in patients with DMD ${ }^{66}$ ) The value for each parameter decreases with disease progression, suggesting that a decrease in parasympathetic tone may parallel disease progression. A decrease in heart rate variability, as measured by the SD of the RR intervals, may be a marker for sudden death. ${ }^{67,68)}$ We showed an increasing incidence of ventricular arrhythmias with the progression of myocardial involvement in DMD. ${ }^{38,45,66)}$ The previous studies indicated an association between ventricular arrhythmias and sudden death. ${ }^{69,70)}$ Although we have not confirmed this association for DMD, ${ }^{66}$ the genesis of ventricular arrhythmias in DMD may be more complex and influenced by factors other than autonomic outflow to the heart. Compared with controls, DMD patients had higher mean heart rates, and the day-night difference was blunted. The coefficient of variance in heart rate variability decreased according to advancing the severity of DMD. This result suggests that reduction in heart rate variability is not proportional to the shortening of RR intervals in the DMD group. A decrease in parasympa- 
thetic activity and some increase in sympathetic activity may exist in DMD.

Frequency domain measurements and circadian rhythm: Spectral analysis of heart rate variability provides an index of sympathetic and parasympathetic activity. ${ }^{71,72)}$ We showed that patients with DMD had a higher LF/HF ratio and smaller HF component than normal controls, suggesting an enhanced sympathetic and reduced vagal activity. ${ }^{66)}$ The trends became more marked with advancing severity of DMD. The controls had an increase in the HF component and a reduction in the $\mathrm{LF} / \mathrm{HF}$ ratio at night, and those trends were absent in patients with DMD. It was noteworthy that the subgroup with severe DMD had an increased LF/HF ratio at night, suggesting an enhanced sympathetic tone, opposite to findings in controls. Sympathetic activity in patients with heart failure is increased throughout the day, with a resulting loss of circadian variability. ${ }^{73)}$ However, the circadian rhythm seen in the patient with severe DMD has not been described in a patient with heart failure. ${ }^{74,75)}$

\section{A 10-year follow-up study:}

Sequential changes of the QRS. A 10-year follow-up study by orthogonal Frank lead electrocardiography was performed on 25 patients with DMD. ${ }^{76)}$ The most remarkable ECG changes were the decreases in amplitudes of $\mathrm{R}$ waves in lead $\mathrm{X}(\mathrm{Rx})$ and in lead $\mathrm{Y}(\mathrm{Ry})$ and an increase in amplitude of $\mathrm{S}$ waves in lead $\mathrm{X}(\mathrm{Sx})$. The decrease in the $\mathrm{Rx}$ amplitude had already been noted in our previous 3-year follow-up study ${ }^{16)}$ in which a decrease in Ry amplitude and increase in Sx were not demonstrated. The $\mathrm{Rx}$ amplitude tended to decline gradually with advancing years, but the Ry amplitude began to show a significant reduction from the seventh year after initiation of the 10-year follow-up study. We speculated that chest deformities, which are observed in almost all patients with moderate to advanced DMD, shifted the heart to the right, possibly resulting in a decrease in the leftward QRS force. Indeed, the transverse diameter and the transverse diameter/sagittal diameter ratio tended to increase with advancing clinical severity. However, in a previous study, ${ }^{17}$ ) we found that an increase in the transverse diameter led to an increase, rather than a decrease, in $\mathrm{Rx}$ amplitude and that the transverse diameter/sagittal diameter ratio did not influence the $\mathrm{Rx}$ amplitude. Close evaluation of each patient ruled out a direct correlation between the reduction of the Rx and Ry amplitudes and the degree of chest deformity. Heymsfield and his coworkers ${ }^{18)}$ were unable to ascribe ECG changes in DMD to pectus excavatum, which is frequently associated with this disorder. It seems likely therefore that the chest deformities may not be the main determinant of the reduction of the leftward and the inferior QRS force, although they might be partially involved. Sanyal et al. ${ }^{19)}$ revealed that progression of the disease tended to be associated with myofibrillar loss in the left ventricular wall, which may account for a significant reduction in the leftward QRS force. Frankel and Rosser ${ }^{20)}$ 
reported that in patients with DMD histologic evidence of degenerative changes appeared initially in the posterobasal segment of the left ventricle, spread subsequently to the outer third of the left ventricular free wall, and finally manifested itself as diffuse transmural fibrosis. Their observations may substantiate our finding that an anterior shift of the QRS force appeared in the early stages, followed by a decrease in the leftward and inferior QRS forces with progression of the disease. In our present state of knowledge, we may be justified in inferring from these results that the decrease in the leftward and inferior QRS forces results mainly from myofibrillar loss in the left ventricular free wall, and that progressive reduction of the $\mathrm{Rx}$ amplitude and abrupt reduction of the $\mathrm{Ry}$ amplitude are useful for assessing the extent of cardiac involvement.

The duration of the QRS complex was slightly prolonged in the advanced stages. $^{76\rangle}$ Ronan et al. ${ }^{24)}$ also reported prolongation of the QRS complex. Abnormalities in the conducting system of the heart and marked myocardial involvement are considered to be a cause of such prolongation of the QRS complex.

Sequential change of the $Q$ wave. The amplitude of the $Q$ wave in lead $Z(Q z)$ is determined by the sum of the anterior electrical activity and posterior electrical activity. Thus, if the posterior electrical activity is reduced by myocardial involvement of the posterior wall, the anterior electrical activity will increase with a resultant increase in the $\mathrm{Qz}$ amplitude. On the other hand, if the anterior wall becomes involved, the anterior electrical activity is reduced, with a consequent decrease in the $Q z$ amplitude. The wide fluctuations in the incidence of the abnormally deep $Q z$ detected in our study ${ }^{76}$ might be due to differences in the extent of involvement of the anterior and posterior left ventricular walls. The true pathogenesis of the abnormal $Q$ wave in DMD remains unresolved. However, it does seem most likely that replacement of normal cardiac tissue by fibrosis, with lateral extension of scarring, may explain the presence of the abnormal $Q$ wave. It is of interest to note that the occurrence of the deep $Q$ wave was found to be quite high even in the early stages of DMD, and that it did not bear a direct relation to the sequential evolution of this disease. Consequently, although the presence of the deep $Q$ wave in the early stages of DMD represents a useful ECG sign for the early detection of DMD, it has only a limited value for assessing the extent of cardiac involvement.

Sequential change of the $P$ wave. In our study, ${ }^{76)}$ the duration and amplitude of the $\mathrm{P}$ waves and $\mathrm{PR}$ interval were within the normal range and showed no timeassociated changes. In earlier studies ${ }^{21,77,78)}$ prolongation of the PR interval was reported on standard 12-lead ECGs, but no abnormalities in the $P$ waves have been found on orthogonal lead ECGs. We speculate that abnormal $\mathrm{P}$ waves occur on the standard 12-lead ECG because chest deformities are likely to cause changes in the spatial relationship between the electrode and the heart, but that 
no abnormal $\mathrm{P}$ waves are observed on the orthogonal lead ECG because the effects of chest deformities on the ECG waveforms are much smaller. Recently, we observed that there were no substantial changes in the serum levels of atrial natriuretic peptide among patients at various stages of DMD. ${ }^{79)}$ These findings might indicate that the atrium can remain unaffected, though not totally, by the involvement of $\mathrm{DMD}$ disease process. This seems to be in keeping with our observation that $\mathrm{P}$ wave abnormalities were not found in DMD patients over the 10-year follow-up period.

Sequential change of the $T$ wave. The amplitude of the $T$ wave was found to decrease sequentially ${ }^{\left.{ }^{6}\right)}$ Flattening of the $\mathrm{T}$ wave has been reported by both standard 12-lead ECG ${ }^{21,48,80,81)}$ and orthogonal lead $\mathbf{E C G}^{82)}$ and is considered to be mostly due to myocardial degeneration.

\section{Echocardiographic Findings}

A high prevalence of mitral valve prolapse (MVP) has been reported in patients with DMD. ${ }^{83-85)}$ The most typical echocardiographic findings in MVP is an abrupt posterior motion of the cusp in mid-to-late systole replacing the normal gradual anterior systolic motion of the mitral leaflet. Such a typical finding was not seen in any one of our 89 patients with DMD ${ }^{57}$ Another proposed finding of MVP is pansystolic bowing (or hammocking), in which the mitral leaflets sags posteriorly throughout systole. In our study, ${ }^{57)}$ pansystolic bowing was recognized in 33 of 89 patients $(36.7 \%)$. This prevalence was just intermediate between the $55 \%$ ( 11 of 20 cases) reported by Sanyal et al. ${ }^{84)}$ and $27 \%$ (six of 22 cases) reported by Biddison et al. ${ }^{85}$ ) The echocardiographic features of the pansystolic bowing in the cases of Sanyal et al. ${ }^{84)}$ appeared to be quite similar to those of our cases. The most prominent finding in our study ${ }^{577}$ was a retraction of the anterior mitral leaflets (AML) and posterior mitral leaflets (PML) toward the apex seen in both systole and diastole. Correlation between the present M-mode and twodimensional echocardiographic studies clearly demonstrated that pansystolic bowing on the M-mode echocardiogram was not associated with superior-posterior prolapse into the left atrium, the hallmark of MVP on two-dimensional echocardiograms, but rather with the retraction of the PML towards the apex. The downward retraction of the PML described in our study ${ }^{57)}$ has never been reported as an explanation of pansystolic bowing in DMD. From our observations, it can be postulated that perhaps retraction of the mitral leaflets towards the apex could represent one of the possible causes of pansystolic bowing in other disease states too.

The retraction in diastole of both the AML and PML toward the apex appeared to narrow the outflow tract from the left atrium. As a result, the blood 
flow from the left atrium might easily hit the tips of either the AML and/or the PML, yielding a fluttering of the mitral valves. On the other hand, a flail mitral valve might also be explained by retraction of the PML anteriorly as well as towards the apex. Though the exact mechanism producing such retraction of the mitral leaflets remains unclear, diastolic anterior motion (DAM) of the left ventricular posterior wall might provide a clue.

The fact that abnormal mitral valve echoes were not seen in cases below $\mathrm{S}(4)$ agree with our previous electrocardiographic findings, ${ }^{11,12)}$ in which a reduction of the leftward QRS complexes ${ }^{11}$ was observed less markedly in cases below $\mathrm{S}(4)$ than in cases above $\mathrm{S}(5)$. This could imply that during the early stages from $\mathrm{S}(1)$ to $\mathrm{S}(4)$, cardiac involvement remains minimai. Among the cases above $\mathrm{S}(5)$, however, the prevalences of occurrence of the abnormal mitral valve echoes were almost identical, although there was a slightly higher prevalence in cases of $\mathbf{S}(8)$.

Pathologic studies on the heart in DMD have consistently shown that the mitral valve leaflets and chordae tendinae are normal, ${ }^{19,20,86)}$ except for one report by Biddison et al., ${ }^{85}$ in which autopsy confirmation of myxomatous changes of the mitral valve leaflets was made in two DMD patients with previous clinical and echocardiographic evidence of mitral valve prolapse. Necropsy findings in our seven investigated cases $^{57)}$ did not reveal myxomatous changes of the mitral leaflets. Multifocal degenerative changes principally involving the postero-basal segment of the left ventricular wall and postero-basal segment of the left ventricular wall and posterior papillary muscle are characteristic histologic findings. ${ }^{19,20,86)}$

Although the exact pathophysiology of the heart in DMD has not yet been clarified, it is conceivable that these myocardial derangements cause a change in the mitral valve structures and in myocardial contraction, either or both of which could contribute to the occurrence of pansystolic bowing and the other patterns of abnormal mitral valve echoes recognized in our study. ${ }^{57)}$

MVP is occasionally observed in patients with thoracic skeletal abnormalities such as pectus excavatum, kyphoscoliosis, and shallow chest. ${ }^{87,88)}$ In our study $\left.{ }^{57}\right)$ it is unlikely that thoracic skeletal abnormalities were the main determinant of the abnormal mitral valve motions in DMD, since the latter were rather frequently encountered in cases of $\mathrm{S}(5)$ and $\mathrm{S}(6)$, while marked thoracic skeletal abnormalities were not usually observed.

An early-to-mid systolic click, with or without a late systolic murmur, is the auscultatory hallmark of MVP. In our study, ${ }^{57)}$ however, such characteristic auscultatory findings were not present in any of the patients.

This observation is not in agreement with the results of other investigations, ${ }^{84,85)}$ in which an early-to-mid-systolic click, with or without a late systolic murmur, was frequently encountered in patients with DMD. The absence of such auscultatory manifestations in our cases appears to be quite consistent with 
the echocardiographic finding that pansystolic bowing was due, not to a prolapsing mitral valve, but to downward retraction of the mitral leaflets.

\section{Hemodynamic Findings}

In the terminal stage, a majority of patients with DMD show a severe degree of respiratory failure due to impairment of the respiratory muscles. Respiratory failure, not congestive heart failure, can thus be reasonably considered as the main cause of death in this disease. In other words, it can be postulated that, in a majority of cases, impairment of the respiratory muscles may advance more rapidly and more extensively than that of the myocardium. Several hemodynamic studies were performed on patients with DMD. ${ }^{11,16,89-91)}$ However, none of the patients showed evidence of respiratory failure. It is possible, therefore, that all of these patients were in the stages where respiratory failure had not yet emerged.

We performed right heart catheterization in 8 DMD patients in the advanced stage showing severe respiratory failure, not complicated by infection. ${ }^{92)}$ It was no surprise to find that they had pulmonary hypertension. In general, pulmonary hypertension can be either postcapillary or precapillary. Von Euler et al. ${ }^{93}$ suggested that severe hypoxemia induced constriction of the pulmonary artery, which caused precapillary hypertension, and was promoted by hypercapnia and acidosis.

In the two patients who underwent assisted respiration, pulmonary hypertension, which was observed under spontaneous respiration, disappeared after the use of the respirator. This observation seems to substantiate the hypothesis that constriction of the pulmonary arterioles due to hypoxemia might be mainly responsible for the genesis of pulmonary hypertension in the advanced stage of DMD. The normal pulmonary capillary wedge pressure (PCWP) in 6 of our 8 patients indicated precapillary pulmonary hypertension. In the remaining 2 patients, however, PCWP was elevated despite the absence of symptoms of left heart failure, indicating coexistence of postcapillary as well as precapillary hypertension. Of the 8 patients, 5 showed an elevated right atrial pressure of above 5 $\mathrm{mmHg}$. These findings suggest the possibility that right heart failure due to precapillary pulmonary hypertension may be present or will occur sooner or later in most patients in an advanced stage of DMD.

\section{Atrial Natriuretic Peptide}

Atrial natriuretic peptide (ANP), which was isolated from human atrial muscle cells, was reported to play an important role in the homeostasis of hemo- 
dynamics. ${ }^{94,95)}$ There are three types of ANP, $\alpha, \beta$, and $\gamma, \alpha$-ANP in particular has potent diuretic and hypotensive effects. In patients with congestive heart failure, $\alpha$-ANP secretion increases with elevation of the atrial pressure, resulting in an increase in the plasma concentration..$^{94,95)}$

Our previous study suggests that in the natural history of DMD, plasma $\alpha$ ANP concentration is mildly elevated in many patients and the $\alpha$-ANP level does not become markedly elevated unless hcart failure develops, even though left ventricular performance is severely impaired, but it is markedly elevated in the presence of congestive heart failure. ${ }^{79}$ Although the precise mechanism of $\alpha$-ANP secretion remains obscure, the volume load and pressure load at the left atrial and right atrial levels are considered to be important stimulatory factors in $\alpha$ ANP secretion. ${ }^{96,97)}$

The normal or slightly elevated plasma $\alpha$-ANP levels observed in many of our patients with DMD, despite severe impairment of the cardiac muscle, may be ascribed to the fact that congestive heart failure was absent and the atrial pressure remained normal until the terminal stage because of the characteristic clinical background of this disease. The finding that the plasma $\alpha$-ANP level was markedly elevated in the only patient who had evidence of clinical congestive heart failure supports this view and also suggests that the ability to secrete atrial $\alpha$-ANP is retained until the terminal stage of DMD. ${ }^{79}$ )

Respiratory failure as a result of involvement of the respiratory muscles is also considered important as a cause of mild elevation of the plasma $\alpha$-ANP level in many patients with DMD. We reported that the presence of pulmonary hypertension (mean pulmonary pressure $>40 \mathrm{~mm} \mathrm{Hg}$ ) in five of eight patients with $\mathrm{DMD}$ and elevation of right atrial pressure (mean right atrial pressure $>5 \mathrm{~mm}$ $\mathrm{Hg}$ ) in six of eight patients with DMD classified as SD. ${ }^{8,92)}$ We found that the $\alpha$ ANP level exceeded $80 \mathrm{pg} / \mathrm{m} l$ in three of the patients with respiratory failure. The occurrence of pulmonary hypertension and elevated right atrial pressure thus appear to be likely factors responsible for the increase in the circulating levels of $\alpha$-ANP in patients with DMD. In our previous study, ${ }^{79)}$ three of four patients in whom the $\alpha$-ANP level exceeded $80 \mathrm{pg} / \mathrm{m} l$ died within 2 months as a result of respiratory failure or congestive heart failure. This suggests that a moderate or marked elevation in the resting plasma $\alpha$-ANP level in patients with terminal DMD is a sign of poor prognosis and can serve as an index for the management of DMD.

\section{REFERENCES}

1. Perloff JK, De Leon AC, O'Doherty D. The cardiomyopathy of progressive muscular dystrophy. Circulation 1966; 33: 625-48.

2. Ishihara T, Kawamura J, Sasaki A, Aoyagi A. Relationship between cardiac and pulmonary function 
in late stage of Duchenne muscular dystorphy patients. Acta Cardiomiologica 1991; 3: 357-65.

3. Langner PH, Geselowitz DB, Mansure FT. High-frequency components in the electrocardiograms of normal subjects and of patients with coronary heart disease. Am Heart J 1961;62; 746-55.

4. Langner $\mathrm{PH}$, Geselowitz DB, Briller SA. Wide band recording of the electrocardiogram and coronary heart disease. Am Heart J 1973; 86: 308-17.

5. Flowers NC, Horan LG, Thomas JR, Tolleson WJ. The anatomic basis for high-frequency components in the electrocardiogram. Circulation 1969; 39: 531-9.

6. Flowers NC, Horan LG. Diagnostic import of QRS notching in high-frequency electrocardiograms of living subjects with heart disease. Circulation 1971; 44: 605-11.

7. Reynolds EW, Muller BF, Anderson GJ, Muller BT. High-frequency components in the electrocardiogram: a comparative study of normals and patients with myocardial disease. Circulation 1967; 35: 195206.

8. Pipberger HV, Zahar SA, Pipberger HA. Diagnostic information derived from high-frequency components in the electrocardiogram. In: Antaloczy Z, editor. Modern Electrocardiology. Amsterdam: Excerpta Medica, 1978: 165-70.

9. Boyle D, Carson $\mathrm{P}$, Hamer J. High frequency electrocardiography in ischaemic heart disease. $\mathrm{Br}$ Heart J 1966; 28: 539-45.

10. Swinyard CA, Deaver GG, Grenspan L. Gradient of functional ability of importance in rehabilitation of patients with progressive muscular and neuromuscular diseases. Arch Phys Med 1957; 38: 574-9.

11. Ishikawa $\mathrm{K}$, Kanemitsu H, Ishihara $\mathrm{T}, \mathrm{T}_{\text {amura }} \mathrm{T}$, Shimada $\mathrm{H}$, Inoue $\mathrm{M}$. Orthogonal electrocardiographic study on progressive muscular dystrophy of the Duchenne type. J Electrocardiol 1979; 12: 1637.

12. Ishikawa $\mathrm{K}$, Shirato $\mathrm{C}$, Yotsukura M, Ishihara $\mathrm{T}$, Tamura $\mathrm{T}$, Inoue M. Sequential changes in high frequency notches on QRS complexes in progressive muscular dystrophy of the Duchenne type: a 3year follow-up study. J Electrocardiol 1982; 15: 23-30.

13. Oppenheimer BS, Rothchild MA. Electrocardiographic changes associated with myocardial involvement. JAMA 1917; 69: 429-31.

14. Casella C, Taccardi B. The spread of excitation over short distances in heart muscle. In: Taccardi B and Marchetri G, editors. Electrophysiology of the Heart. New York: Pergamon Press, 1965; 153-61.

15. VanderArk CR, Reynolds EW. Genesis of high frequency notching of QRS complexes in vivo cardiac model. Circulation 1975; 51: 257-62.

16. Ishikawa K, Yanagisawa A, Ishihara T, Tamura T, Inoue M. Sequential changes of orthogonal electrocardiograms in progressive muscular dystrophy of the Duchenne type. Am Heart J 1979; 98: 7382.

17. Ishikawa $\mathrm{K}$. Correlation coefficients for electrocardiographic and constitutional variables. Am Hcart J 1976; 92: 152-61.

18. Heymsfield SB, McNish T, Perkins JV, Felner JM. Sequence of cardiac changes in Duchenne muscular dystrophy. Am Heart J 1978; 95: 283-94.

19. Sanyal SK, Johnson WW, Thapar MK, Pinter SE. An ultrastructural basis for electrocardiographic alterations associated with Duchenne's progressive muscular dystrophy. Girculation 1978; 57: 1122-9.

20. Frankel KA, Rosser RJ. The pathology of the heart in progressive muscular dystrophy. Epimyocardial fibrosis. Hum Pathol 1976; 7: 375-86.

21. Weisenfeld $\mathrm{S}$, Messinger WJ. Cardiac involvement in progressive muscular dystrophy. Am Heart $\mathrm{J}$ 1952; 43: 170-87.

22. Manning GW, Cropp GJ. The electrocardiogram in progressive muscular dystrophy. Br Heart J 1958; 20: $416-20$.

23. Perloff JK, Roberts SC, deLeon AC Jr, O'Doherty D. Distinctive electrocardiogram of Duchenne's progressive muscular dystrophy. Am J Med 1967; 42: 179-188.

24. Ronan JA Jr, Perloff JK, Bowen PJ, Mann O. The vectorcardiogram in Duchenne' progressive muscular dystrophy. Am Heart J 1972; 84: 588-96.

25. Rozanski JJ, Mortara D, Myerber RJ, Castellanos A. Body surface detection of delayed depolarizations in patients with recurrent ventricular tachycardia and left ventricular aneurysm. Circulation 1981; 63: $1172-8$. 
26. Simson MB. Use of signals in the terminal QRS complex to identify patients with ventricular tachycardia after myocarial infarction. Circulation 1981; 64: 235-42.

27. Simson MB, Untereker WJ, Spielman SR, et al. Relation between late potentials on the body surface and directly recorded fragmented electrograms in patients with ventricular tachycardia. Am J Cardiol 1983; 51: 105-12.

28. Kanovsky MS, Falcone RA, Dresden CA, Josephson ME, Simson MB. Identification of patients with ventricular tachycardia after myocardial infarction: signal-averaged electrocardiogram, Holter monitoring, and catheterization. Circulation 1984; 70: 264-70.

29. Marcus NH, Falcone RA, Harken AF, Josephson ME, Simson MB. Body surface late potentials: effects of endocardial resection in patients with ventricular tachycardia. Girculation 1984; 70: 632-7.

30. Freedman RA, Gillis AM, Keren A, Soderholm-Difatte V, Mason JW. Signal-averaged electrocardiographic late potentials in patients with ventricular fibrillation or venricular tachycardia: correlation with clinical arrhythmia and electrocardiographic study. Am Heart J 1985; 55: 1350-3.

31. Gomes JA, Mehra R, Barreca P, El-Sherif N, Hariman R, Holtzman R. Quantitative analysis of the high-frequency components of the signal-averaged $Q R S$ complex in patients with acute myocardial infarction: a prospective study, Circulation 1985; 72: 105-11.

32. Denniss AR, Johnson DC, Richards DA, Ross DL, Uther JB. Effect of excision of ventricular myocardium on delayed potentials detected by the signal-averaged electrocardiogram in patients with ventricular tachycardia. Am J Cardiol 1987; 59: 591-5.

33. Nalos PC, Gang ES, Mandel WJ, Ladenheim ML, Lass Y, Peter T. The signal-averaged electrocardiogram as a screening test for inducibility of sustained ventricular tachycardia in high risk patients: a prospective study. J Am Coll Cardiol 1987; 9: 539-48.

34. Winters SL, Stewart D, Gomes JA. Signal averaging of the surface QRS complex predicts inducibility of ventricular tachycardia in patients with syncope of unknown origin: a prospective study. $\mathrm{J} \mathrm{Am} \mathrm{Coll}$ Cardiol 1987; 10: 775-81.

35. Buckingham TA, Ghosh S, Homan SM, et al. Independent value of signal-averaged electrocardiography and left ventricular function in identifying patients with sustained ventricular tachycardia with coronary artery disease. Am J Cardiol 1987; 59: 568-72.

36. Poll DS, Marchlinski FE, Falcon RA, Josephson ME, Simson MB. Abnormal signal-averaged electrocardiograms in patients with nonischemic congestive cardiomyopathy: relationship to sustained ventricular tachyarrhythmias. Circulation 1985; 72: 1308-13.

37. Coto H, Maldonado C, Palakurthy P, Flowers NC. Late potentials in normal subjects and in patients with ventricular tachycardia unrelated to myocardial infarction. Am J Cardiol 1985; 55: 384-90.

38. Yotsukura M, Ishizuka T, Shimada T, Ishikawa K. Late potentials in progressive muscular dystrophy of the Duchenne type. Am Heart J 1991; 121: 1137-42.

39. Breithardt G, Borggrefe M, Karbenn U, Abendorth R, Yeh H, Seipel L. Prevalence of late potentials in patients with and without ventricular tachycardia: correlation with angiographic findings. Am $\mathrm{J}$ Cardiol 1982; 49: 1932-37.

40. Zimmermann M, Adamec R, Simonin P, Richez J. Prognostic significance of ventricular late potentials in coronary artery disease. Am Heart $J$ 1985; 109: 725-32.

41. Abboud S, Belhassen B, Laniado $S$, Sadeh D. Non-invasive recording of late ventricular activity using an advanced method in patients with a damaged mass of ventricular tissue. J Electrocardiol 1983; 16: 245-5l.

42. Gomes JA, Horowitz SF, Millner M, Machac J, Winters SL, Barreca P. Relation of late potentials to ejection fraction and wall motion abnormalities in acute myocardial infarction. Am J Cardiol 1987; 59: 1071-4.

43. Fenoglio JJ, Pham TD, Harken AH, Horowitz LN, Josephson ME, Wit AL. Recurrent sustained ventricular tachycardia: structure and ultrastructure of subendocardial regions in which tachycardia originates. Circulation 1983; 68: 518-33.

44. James TN. Observations on the cardiovascular involvement, including the cardiac conduction system, in progressive muscular dystrophy. Am Heart J 1962; 63: 48-56.

45. Yanagisawa A, Miyagawa M, Yotsukura M, et al. The prevalence and prognostic significance of arrhythmias in Duchenne type muscular dystrophy. Am Heart J 1992; 124; 1244-50. 
46. Rubin IL, Buchberg AS. The heart in progressive muscular dystrophy. Am Heart J 1952; 43: 161-9.

47. Perloff JK. Cardiac rhythm and conduction in Duchenne's muscular dystrophy: a prospective study of 20 patients. J Am Coll Cardiol 1984; 3: 1263-8.

48. Slucka C. The electrocardiogram in Duchenne progressive muscular dystrophy. Circulation 1968; 38; 933-40.

49. Sanyal SK, Johnson WW. Cardiac conduction abnormalities in children with Duchenne's progressive muscular dystrophy: electrocardiographic features and morphologic correlates. Circulation 1982; 66: 853-63.

50. Brodsky M, Wu D, Denes P, Kanakis C, Rosen KM. Arrhythmias documented by 24-hour continuous electrocardiographic monitoring in 50 male medical students without apparent heart disease. Am J Cardiol 1977; 39: 390-5.

51. Southall DP, Johnston F, Shinebourne EA, Johnston PGB. 24-hour electrocardiographic study of heart rate and rhythm patterns in population of healthy children. Br Heart J 1981; 45: 281-9l.

52. Demany MA, Zimmerman HA. Progressive muscular dystrophy: hemodynamic, angiographic, and pathologic study of a patient with myocardial involvement. Circulation 1969; 40:377-84.

53. Zalman F, Perloff JK, Durrant NN, Campion DS. Acute respiratory failure following intravenous verapamil in Duchenne's muscular dystrophy. Am Heart J 1983; 105: 510-1.

54. Yotsukura M, Miyagawa M, Tsuya T, Ishihara T, Ishikawa K. Pulmonary hypertension in progressive muscular dystrophy of Duchenne type. Jpn Circ J 1988; 52: 321-6.

55. Scott O, Williams GJ, Fiddler GI. Results of 24-hour ambulatory monitoring of electrocardiogram in 131 healthy boys aged 10 to 13 years. Br Heart J 1980; 44: 304-8.

56. Bensaid H, Marsaud G, Monassier JP, Blanc G. High degree atrioventricular block associated with Wolf-Parkinson-White syndrome during Duchenne de Boulogne type myopathy. Ann Cardiol Angeiol (Paris) $1975 ; 24: 67-74$.

57. Ishikawa $K$, Hirata $S$, Shimada $\mathbf{H}$, Ishihara $T$, Tamura $T$, Inoue $M$. Evaluation of mitral valves in patients with progressive muscular dystrophy of the Duchenne type by two dimensional and M-mode echocardiography. J Cardiovasc Ultrasonogr 1983; 2: 35-43.

58. Lown B, Wolf M. Approaches to sudden death from coronary heart disease. Circulation 1971; 44: 130-42.

59. Hardarson T, de la Calzada CS, Curiel R, Goodwin JF. Prognosis and mortality of hypertrophic obstructive cardiomyopathy. Lancet 1973; 2: 1462-7.

60. Perloff JK, Moise NS, Stevenson WG, Gilmour RF. Cardiac electrophysiology in Duchenne muscular dystrophy: from basic science to clinical expression. J Cardiovasc Electrophysiol 1992; 3: 394-409.

61. Lishner M, Akselrod S, Mor Avi V, Oz O, Divon M, Ravid M. Spectral analysis of heart rate fuctuations: a non-invasive sensitive method for the early diagnosis of autonomic neuropathy in diabetes mellitus. J Auton Nerv Syst 1987; 19: 11925.

62. Ewing DJ, Neilson JM, Shapiro CM, Stewart JA, Reid W. Twenty-four hour heart rate variability: effects of posture, sleep and time of day in healthy controls and comparison with bedside tests of autonomic function in diabetic patients. Br Heart J 1991; 65: 239-44.

63. Kleiger R, Miller JP, Bigger JT, Moss AJ, Multicenter Post-Infarction Research Group. Decreased heart rate variability and its association with increased mortality after acute myocardial infarction. Am J Cardiol 1987; 59: 256-62.

64. Bigger JT, Fleiss JL, Steinman RC, Rolnitzky LM, Kleiger RE, Rottman JN. Frequency domain measures of heart rate period variability and mortality after myoccardial infarction. Circulation 1992; 85: $164-71$.

65. Lombardi F, Sandrone G, Pernpruner S, et al. Heart rate variability as an index of sympathovagal interaction after myocardial infarction. Am J Cardiol 1987; 60: 1239-45.

66. Yotsukura M, Sasaki K, Kachi E, Sasaki A, Ishihara T, Ishikawa K. Circadian rhythm and variability of heart rate in Duchenne type progressive muscular dystrophy. Am J Cardiol 1995; 76: 947--51.

67. Huikuri HV, Kessler KM, Terracall E, Castellanos A, Linnaluoto KM, Myerburg RJ. Reproducibility and circadian rhythm of heart rate variability in healthy subjects. Am J Cardiol 1990; 65: 391-3.

68. Martin GJ, Mgaid NM, Myers G, et al. Heart rate variability and sudden death secondary to coronary artery disease during ambulatory electrocardiographic monitoring. Am J Cardiol 1987; 60: 86-9. 
69. Meinertz T, Hofmann $T$, Kasper $W$, et al. Significance of ventricular arrhythmias in idiopathic dilated cardiomyopathy. Am J Cardiol 1984; 15: 902-7.

70. Mesineo FC. Ventricular ectopic activity: prevalence and risk. Am J Cardiol 1989; 64: 53J-56J.

71. Akselrod S, Gordon D, Ubel FA, Shannon DC, Barger AC, Cohen RJ. Power spectrum analysis of heart rate fluctuation: a quantitative probe of beat-to-beat cardiovascular control. Science 1981; 213 : $220-2$.

72. Malliani A, Pageni M, Lombardi F, Cerutti S. Cardiovascular neural regulation explored in the frequency domain. Girculation 1991; 84: 482-92.

73. Casolo G, Balli E, Tadderi T, Amuhasi J, Gori C. Decreased spontaneous heart rate variability in congestive heart failure. Am J Cardiol 1989; 64: 1162-47.

74. Hoogenhuyze DV, Weinstein N, Martin GJ, et al. Reproducibility and relation to mean heart rate of heart rate variability in normal subjects and in patients with congestive heart failure secondary to coronary artery disease. Am J Cardiol 1991; 68: 1668-76.

75. Casolo G, Balli E, Fazi A, Gori C, Freni A, Gensini G. Twenty-four-hour spectral analysis of heart rate variability in congestive heart failure secondary to coronary artery disease. Am J Cardiol 1991; 67: $1154-8$.

76. Yotsukura M, Miyagawa M, Tsuya T, Ishihara T, Ishikawa K. A 10-year follow-up study by orthogonal Frank lead ECG on patients with progressive muscular dystrophy of the Duchenne type. J Electrocardiol 1992; 25: 345-53.

77. Lukasik E, Liszewska-Pfejfer D, Rubach K, Szwed H. Long-term electrocardiographic studies in patients with Duchenne progressive muscular dystrophy. Act Med Pol 1980; 21: 181-91.

78. Wahi PL. Cardiac changes in myopathy. Am Heart J 196; 66: 748-54.

79. Yanagisawa A, Yokota N, Miyagawa M, Kawamura J, Ishihara T, Aoyagi T, Ishikawa K. Plasma levels of atrial natriuretic peptide in patients with Duchenne's progressive muscular dystrophy. Am Heart J 1992; 120: 1154-8.

80. Gilroy J, Cahalan JL, Berman R, Newman M. Cardiac and pulmonary complications in Duchenne's progressive muscular dystrophy. Circulation 1963; 27: 484-93.

81. Berenbaum AA, Horowitz W. Heart involvement in progressive muscular dystrophy, report of a case with sudden death. Am Heart J 1956; 51: 622-7.

82. Fitch CW, Ainger LE. The Frank vectorcardiogram and the electrocardiogram in Duchenne progressive muscular dystrophy. Circulation 1967; 35: 1124.

83. Reeves W, Griggs R, Nanda ND, Gramiak R. Echocardiographic demonstration of mitral valve prolapse in muscular dystrophy. Circulation 1976; 54 (supp. II) II-97.

84. Sanyal SK, Leung RKF, Tirney EC, Gilmartin R, Pinter S. Mitral valve prolapse syndrome in children with Duchenne's progressive muscular dystrophy. Pediatrics 1979; 63: 116-23.

85. Biddison JH, Dembo DH, Spalt H, Hayes MG, LeDoux GW. Familial occurrence of mitral valve prolapse in X-linked muscular dystrophy. Circulation 1979; 59: 1299-304.

86. Sanyal SK, Johnson WW, Desche ME, Pitner SE, Beard C. Dystrophic degeneration of papillary muscle and ventricular myocardiurn: a basis for mitral valve prolapse in Duchenne's muscular dystrophy. Circulation 1980; 62: 430-8.

87. Salomon J, Shah PM, Heinle RA. Thoracic skeletal abnormalities in idiopathic mitral valve prolapse. Am J Cardiol 1975; 36: 32-6.

88. Bon Tenpo CP, Ronan JA, DeLeon AC, Twigg HL. Radiographic appearance of the thorax in systolic click-late systolic murmur syndrome. Am J Cardiol 1975; 36: 27-31.

89. Gairani S, Danowski TS, Fisher DS. Muscular dystrophy catheterization studies indicating latent congestive heart failure. Circulation 1958; 17: 583-8.

90. Rubeiz GA, Saab NG. Hemodynamic study in a case of progressive muscular dystrophy involving the heart. Am J Cardiol 1962; 10: 890-3.

91. Wahi PL, Bhargave KC, Mohindra S. Cardiorespiratory changes in progressive muscular dystrophy. Brit Heart J 1971; 33: 533-7.

92. Yotsukura M, Miyagawa M, Tsuya T, Ishihara T, Ishikawa K. Pulmonary hypertension in progressive muscular dysrophy of the Duchenne type. Jap Circul J 1988; 52: $321-6$.

93. Von Euler US, Liljestrand G. Observations on the pulmonary artery blood pressure in the cat. Acta 
Physiol Scand 1946; 12: 301-20.

94. Fyhrguist F, Tikkanen I. Atrial natriuretic peptide in congestive heart failure. Am J Cardiol 1988; 62: 20A-24A.

95. Creager MA, Hirsch AT, Nabel EG, Cutler SS, Cokucci WS, Dzau VJ. Responsiveness of atrial natriuretic factor to reduction in right atrial pressure in patients with chronic congestive heart failure. $J$ Am Coll Cardiol 1988; 11: 1191-8.

96. Waldman HM, Palacios IF, Block PC, et al. Responsiveness of plasma atrial natriuretic factor to shortterm changes in left atrial hemodynamics after percutaneous balloon mitral valvuloplasty. $\mathrm{J}$ Am Coll Cardiol 1988; 12: 649-55.

97. Riegger GA, Elsner D, Kromer EP, et al. Atrial natriuretic peptide in congestive heart failure in the dog: plasma levels, cyclic guanosine monophosphate, ultrastructure of atrial myoendocrine cells, and hemodynamic, hormonal, and renal effects. Circulation 1988; 77: 398-406. 